\title{
«LAS AVES Y ANIMALES DE LA OSCURA Y ENCANTADA SELVA DO HABITAMOS»: TIPOLOGÍA Y FUNCIÓN DE LOS ANIMALES EN LA NOVELA PASTORIL ESPAÑOLA
}

\author{
«LAS AVES Y ANIMALES DE LA OSCURA Y ENCANTADA SELVA DO \\ HABITAMOS»: TIPOLOGY AND FUNCTION OF ANIMALS IN SPANISH \\ PASTORAL NOVEL
}

\author{
Francisco JaVier GonZÁlez García
}

\begin{abstract}
RESUMEN
En este trabajo se analizan las figuras de animales reales presentes en la novela pastoril española de los siglos XVI y XVII, género inaugurado por Jorge de Montemayor con la obra Los siete libros de la Diana (1559). A esta siguió una veintena de obras, cuyo género llegará hasta las tres primeras décadas del siglo XVII. En todas ellas se refiere gran variedad de animales, cuya función suele ser siempre la misma. Sin embargo, a medida que el género evoluciona, aparecen animales fabulosos, tales como las serpientes y perros gigantes.

Palabras Clave: animales, pastoril, novela, ovejas, aves.
\end{abstract}

\section{Abstract}

In this paper it is analyzed the figures of real animals in the Spanish pastoral novel of the sixteenth and seventeenth centuries, genre inaugurated by Jorge de Montemayor with the work Los siete libros de la Diana (1559), and many will come to the first three decades of the seventeenth century. They refer variety of animals, whose role is usually always the same in all of them. However, as the genre evolves, fabulous animals, such as snakes and giant dogs appear.

KEY WORDS: animals, pastoral, novel, sheeps, birds.

\section{INTRODUCCIÓN}

Cuando se habla de novela pastoril hay que pensar, ante todo, que se está hablando de uno de los géneros narrativos más importantes de los Siglos de Oro de Recibido: 22-03-2016 / Aceptado: 20-09-2016. 
la literatura española ${ }^{1}$. Como en cualquier otra manifestación artística de las letras de Occidente, son muchos los antecedentes en los que el pastor y el ambiente característico que lo rodea está presente en mayor o menor medida. Podemos, así, remontarnos a los Idilios de Teócrito o las Bucólicas de Virgilio, a la Arcadia de Sannazzaro, al officium del teatro medieval, así como a ciertos autores místicos renacentistas o a las églogas de Garcilaso de la Vega, todas ellas creaciones que toman al pastor y sus circunstancias como motivo central. A este respecto, matiza uno de los mejores críticos de este género literario ${ }^{2}$ :

Así, el género literario pastoril agruparía un vasto cúmulo de obras desde Grecia y Roma a través de las literaturas europeas, en las cuales se establecería la consideración del «pastor» como ente que condiciona de un modo u otro por su naturaleza la obra de creación literaria que a él se refiera.

Este ideal, tan del gusto del Renacimiento, acaba imponiéndose como género narrativo a mitad de siglo. Sin embargo, no tuvo la vigencia de los libros de caballerías, pues ni siquiera duró cien años, sino que su llama se apagó por completo bien entrado el siglo XVII. No voy a tratar aquí las causas de tal desaparición. Baste decir que la enjundia del género coincide con su primera manifestación como tal en nuestras letras con Los siete libros de la Diana de Jorge de Montemayor en 1559 hasta llegar (siempre de un modo relativo) a La Galatea de Miguel de Cervantes en 1585.

Este es el contexto de los animales de este género literario, cuya tipología y función analizo a continuación en algunas muestras.

\section{LOS ANIMALES EN LA NOVELA PASTORIL ESPAÑOLA}

Si nos detenemos a analizar el corpus de los llamados libros de pastores, observaremos que en todos ellos están presentes, en mayor o menor medida, los animales. Muchos de estos son comunes, al menos en los inicios del género, en todas las obras, que, posteriormente, ya entrados en el siglo XVII, experimentan varias modificaciones.

\subsection{Animales comunes}

Hay una serie de animales que constituyen la fauna estereotipada de la novela pastoril, sin los cuales muchas de las funciones genuinas de estas piezas dejarían de existir. Así, en primer lugar, aves, ovejas y cabras siempre redundan en la acción,

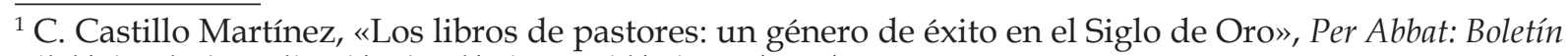
Filológico de Actualización Académica y Didáctica, 6 (2008), pp. 9-28.

${ }^{2}$ F. López Estrada, Los libros de pastores en la literatura española. La órbita previa, Madrid, Gredos, 1974, pp. 18-19. 
aunque los lectores no se percaten de su presencia más que por un sutil comentario del narrador.

\subsubsection{AVES}

Típica es la presencia de las aves, las cuales tienden a cantar gozosas en el locus amoenus en el que actúan los pastores. ¿Cuál es la función de estos animales? Unas veces no sirven más que de relleno o adorno para constituir un paraje ideal, del tipo que refiere fray Luis de León en De los nombres de Cristo: «Las aves con su canto y la hierba con su frescura les deleitan y sirven» ${ }^{3}$.

En otras ocasiones, encontramos que la actitud de las aves está en correspondencia con el estado anímico del pastor del que se trate en ese momento, como ocurre en este pasaje de La Galatea (1585) de Cervantes, en el que las aves no solo están contentas, sino que, además, saludan con su canto al recién llegado pastor:

Cuando Elicio acabó su canto, comenzaba a descubrirse por las orientales puertas la fresca aurora con sus hermosas y variadas mejillas, alegrando el suelo, aljofarando las yerbas y pintando los prados, cuya deseada venida comenzaron luego a saludar las parleras aves con mil suertes de concertadas cantilenas ${ }^{4}$.

Al contrario, si el pastor está triste y pesaroso por algún desamor, entonces las aves funcionan como confidentes que escuchan el lamento del personaje. Valga de ejemplo la pesadumbre de Diana en Diana Enamorada (1564) de Gil Polo:

Pero después que el ánimo cobró algún tanto su vigor, fue tan grande la fuerza de su pasión y el ímpetu con que amor reinaba en sus entrañas, que le forzó publicar su tormento a las simples avecillas, que de los floridos ramos la escuchaban, a los verdes árboles que de su congoja parece que se dolían, y a la clara fuente $[\ldots]^{5}$.

También en consonancia con la acción, es frecuente, sobre todo en los inicios del género, presenciar aves que se sorprenden y conmocionan por el bello canto de algún personaje, como cuenta el pastor Silvano en La Diana de Montemayor (1539) de su enamorada:

Debía ella entonces imaginar en su triste soledad y en el mal que tu ausencia le hacía sentir; pero de ahí a un poco, no sin lágrimas acompañadas de tristes suspiros, sacó una zampoña que en el zurrón traía y la comenzó a tocar tan dulcemente que el valle, el monte, el río, las aves enamoradas, y aun las fieras de aquel espeso

\footnotetext{
${ }^{3}$ Fray L. de León, De los nombres de Cristo, Federico de Onís (ed.), Madrid, Clásicos Castellanos, vol. I, 1914, p. 128.

${ }^{4}$ M. de Cervantes Saavedra, La Galatea, Francisco López Estrada y María Teresa López García-Berdoy (eds.), Madrid, Cátedra, 1995, pp. 627-628.

${ }^{5}$ G. Gil Polo, Diana enamorada, Francisco López Estrada (ed.), Madrid, Castalia, 1987, pp. 90-91.
} 
bosque, quedaron suspensas ${ }^{6}$.

Similar a las del Pastor de Fílida (1582) de Montalvo, donde el pastor cazador argumenta su habilidad con la caza, mediante una hipérbole en la que intervienen las aves:

[...] y cazo el bosque hondo y la sierra alta.

Con arcos, perchas, redes y ventores,

ni basta al ave el vuelo presuroso

ni se me van los ciervos corredores ${ }^{7}$.

Yendo más allá — si bien, en general, se habla de aves, sin matiz - , hay casos en los que se alude a un tipo en concreto, como el mirlo, el cuervo, la calandria, el ruiseñor, etc.

\subsubsection{EL GANADO: OVEJAS, CABRAS Y CORDEROS}

Puesto que todos los personajes que intervienen - en principio - son pastores, es evidente que aparezca el ganado, compuesto de ovejas y, frecuentemente, también de cabras. No obstante, el narrador no suele aludir a ellas más que al inicio del capítulo o libro, cuando el pastor en cuestión llega, y al final, cuando, llegado el momento en que el sol declina, recoge el ganado y se marcha ${ }^{8}$.

La característica principal de las ovejas de estas novelas es la mansedumbre: nunca se que quejan ni molestan, sino que se limitan a pastar, ajenas a cualquier problema. Así se muestra en Los diez libros de fortuna de Amor (1573) de Lo Frasso: «Florineo, como bueno y leal servidor, se puso luego en camino y halló a la pastora Fortuna que miraba sus mansas ovejas, que, en la orilla del río, dulcemente, unas bebían y otras, de las tiernas hierbas, comían» ${ }^{9}$.

Ocasionalmente, la presencia de las ovejas produce en el pastor sentimientos de diversa índole, generalmente negativos, como sucede en cierto episodio de La Diana de Montemayor, en la que Sireno se conmueve cuando acuden las ovejas de Diana:

Pues las ovejas no menos sentimiento hicieron, porque la borrega mayor, con su rústico cencerro, se vino al pastor, y todas las otras, guiadas por el amo por el conocimiento de Sireno, le cercaron alrededor, cosa que él no pudo ver sin

\footnotetext{
${ }^{6}$ J. de Montemayor, La Diana, Juan Montero (ed.), Barcelona, Crítica, 1996, pp. 26-27.

${ }^{7}$ L. Gálvez de Montalvo, El pastor de Fílida, Miguel Ángel Martínez San Juan (ed.), Universidad de Málaga, Servicio de Publicaciones e Intercambio, 2007, p. 451.

${ }^{8}$ A este respecto, cfr. Krauss (1967, p. 364), según el cual el trasfondo real de la novela pastoril está en relación directa con el carácter trashumante de los pastores reales a la sazón.

${ }_{9}^{9}$ A. de Lo Frasso, Los diez libros de Fortun de amor, Antonello Murtas (ed.), Cagliari, Centro di Studi Filologici Sardi CUEC, 2012, p. 91. 
lágrimas, acordándosele que, en compañía de la hermosa pastora Diana, había repastado aquel rebaño ${ }^{10}$.

Como queda dicho, es posible que en el ganado también haya cabras, o, incluso, que solo haya cabras, como en La enamorada Elisea (1597) de Covarrubias:

Otro día por la mañana, antes que el sol saliesse, ya la hermosa pastora Elisea bajaba la cuesta de su aldea con sus queridas cabras, guiándolas al acostumbrado sitio donde la menuda yerba, con las blancas y doradas flores esmaltada, el necesario y suficiente pasto ofrecía, y luego que la hermosa y discreta pastora llegó a la ribera del famoso y celebrado Nilo $[\ldots]^{11}$.

Incluso es posible que la imagen de la oveja mansa sirva para crear un contexto de compasión, como en el caso del exilio de Laureno en Desengaño de celos (1594) de López de Enciso, cuyos corderos con diminutivo producen sensación de pequeñez e inocencia, circunstancia que se evidencia apenas iniciada la obra:

Acompañado de celosos pensamientos, con copiosos suspiros y copiosas lágrimas, caminaba el lastimado pastor Laureno, dejando a la mano derecha su querida aldea, volvía, de rato en rato, a mirar los fértiles campos y apacibles riberas, donde con tanto contento cuanto al presente de tristeza llevaba, solía repastar sus mansos $\mathrm{y}$ hermosos corderillos $[\ldots]^{12}$.

Lo más habitual es que el ganado o algún componente sirvan, de forma indirecta e inconsciente, de nexo amoroso entre una pareja de pastores, como ocurre en Ninfas y pastores de Henares (1587) de González de Bobadilla, en que la pastora, al llevar una cabra a beber agua, halla un escrito del pastor amante:

Esta pastora [Fílira], llevando un día su cabrío para un manso arroyo do aplacasse la importunidad de la sed, vio entre las matas un papel algo curiosamente doblado $\mathrm{y}$, con desseo de saber el misterio, le levantó de la tierra y, leyendo el sobrescrito [...], le causó gran turbación, conociendo claramente ser del enamorado Florino ${ }^{13}$.

Pero, a fin de cuentas, la función principal - a la que se subordinan todas las demás - del ganado no es otra que servir de pretexto para que tales personajes puedan ser considerados pastores y poder, así, darse al oficio. Paradójicamente, no al oficio de pastor como tal, en absoluto, pues se desentienden de sus ovejas para, sentados bajo un árbol o junto a una fuente, haya o arrollo, se autolamentan o discuten con otros pastores de sus problemas de amor. Como señalaba fray Juan de los Ángeles:

Los pastores, como tienen los ánimos sencillos y no contaminados con vicios, tienen el amor puro y ordenado a buen fin [...] Al fin, la vida del pastor es inocente

\footnotetext{
${ }^{10}$ A. de Lo Frasso, Los diez libros de Fortun [...], ob. cit., p. 258.

${ }^{11}$ Fol. 4R.

${ }^{12}$ Fol. 1R.

${ }^{13}$ Fol. 44R.
} 
y sossegada y deleitosa; y la condición de su estado es inclinada al amor, y su ejercicio es gobernar, dando pasto y acomodando su gobierno a las condiciones particulares de cada una de sus ovejas ${ }^{14}$.

Sin ir más lejos, frecuentemente los pastores, demasiado ocupados con sus historias amorosas, olvidan el ganado, como ocurre en este fragmento de la Segunda parte de la Diana (1574) de Alonso Pérez, donde la sabia Felicia llama la atención a Silvano y Selvagia por el descuido:

Venturosos pastor y pastora, no dejara de reprehenderos del descuido que tenéis con vuestro ganado si yo no fuera la culpada, pues, en estos días, jamás habéis preguntado ni pienso que habéis tenido acuerdo dél, que tanta falta en la vuestra habéis sentido, y con razón no siendo en las convenientes horas apastado en la verde yerba restauradora del gastado mantenimiento, ni levado en el tiempo a las claras aguas, remedio de la importuna sed, ni guiadas con el debido reglo a las apazibles sombras $[\ldots]^{15}$.

\subsubsection{PERROS, CIERVOS Y LIEBRES}

Todavía en plano más secundario que el de las ovejas, se sitúan los perros que ejecutan la protección del ganado. Generalmente, el tipo concreto de perro que aparece es el mastín, sin mayor matiz. La presencia de estos animales, salvo por algún comentario efímero del narrador, pasa prácticamente inadvertida. En cualquier caso, su función es protectora del rebaño y pueden llegar a ser sobradamente dañinos si algún desconocido se acerca a las ovejas, como le habría sucedido a Sireno en La Diana si los perros no lo hubiesen conocido:

Y como el pastor se parase a mirarlas [a las ovejas], imaginando el tiempo que le habían dado más en que entender que las suyas propias, los mastines con gran furia se vinieron a él; mas, como llegasen, y de ellos fuese conocido, meneando las colas y bajando los pescuezos, que de agudas puntas de acero estaban rodeados, se le echaban a los pies; y otros se le empinaban con el mayor regocijo del mundo ${ }^{16}$.

No menos interés muestra la presencia del ciervo. Si bien no resulta tan habitual como la de los anteriores, no es extraño que un pastor se tope con un ciervo, generalmente, herido, cuyo encuentro sirve, una vez más, de nexo entre futuros amantes. Lo ilustra perfectamente El pastor de Fílida:

Apenas Silvano puso fin a su afligida canción cuando, llamado de un súbito ruido, volvió los ojos al monte y, por la falda dél, vido venir un ligero ciervo herido de dos saetas en el lado izquierdo, sangrientas las blancas plumas, y tan veloz en su

\footnotetext{
${ }^{14}$ Fray J. de los Ángeles, Considerationum espiritualium super libri Cantici Canticorum Salomonis, Madrid, NBAAEE, 1607, xxIV, 182a.

${ }^{15}$ A. Estradé Sánchez, La segunda Diana de Alonso Pérez. Estudio y edición, Tesis Doctoral dirigida por Miguel Álvaro Alonso, Madrid, Universidad Complutense, 2011, p. 10.

${ }^{16}$ A. Estradé Sánchez, La segunda Diana de Alonso Pérez. Estudio y edición, ob. cit., p. 258. 
carrera que sólo el viento se le podía comparar, y, a poco rato que entró por la espesura del bosque, por las pisadas que él había traído, llegaron dos gallardas cazadoras $^{17}$.

Posteriormente, ya entrados en el siglo xVII, el ciervo adquiere una cierta simbología mística u onírica, como el gamo de la historia de Manilva que se transforma en niña, en El premio de la constancia y pastores de Sierra Bermeja (1620) de Espinel Adorno:

Cuando la vieron tan bella y pressurosa, casi todos se abalançaron para acogerla, adelantándose uno más ligero y animoso, que, viéndolo la gama, bolvió su carrera metiéndose por el monte y espesura donde, después de aver corrido algún trecho, se fue a parar y aún a desparecer debaxo de un frondoso y acopado laurel [...]. Cuando entendió coger la gama, que con su carrera le llevó a aquel sitio, se desapareció, y, colgadas de las ramas de aquel laurel, avía hallado aquella niña que tenía en los braços ${ }^{18}$.

Por último, cabe citar el caso de la liebre - cuya asociación simbólica con la lujuria no debe ser pasada por alto ${ }^{19}-$, que, aunque de forma más puntual, dota a la historia de cierta simpatía. Es el caso de la que aparece en La Galatea, que, viéndose perseguida por multitud de perros, se esconde entre los brazos de la pastora, cosa que, de nuevo, produce una relación entre estas y los pastores dueños de los perros:

Y allí, vencida del cansa[n]cio de la larga carrera y casi como segura del cercano peligro, [la liebre] se dejó caer en el suelo con tan cansado aliento que parecía que faltaba poco para dar el espíritu. Los perros, por el olor y rastro, la siguieron hasta entrar adonde estaban las pastoras; mas Galatea, tomando la temerosa liebre en los brazos, estorbó su vengativo intento a los cobdiciosos perros [...]. De allí a poco llegaron algunos pastores, que en seguimiento de los perros y de la liebre venían ${ }^{20}$.

\subsubsection{FIERAS Y ALIMAÑAS}

A menudo, en contraste con los animales «bellos» vistos hasta el momento, se refieren otra suerte de seres de condición más dañina y peligrosa. Digo se refieren porque, con pocas excepciones, no están presentes en la acción real, sino que forman parte de una posibilidad virtual. Muchas veces, las «alimañas», a partir de una hipérbole, como en el mito de Orfeo, se enternecen por los lamentos de los personajes, como sucede con el de Diana en Diana enamorada:

Deste dolor y de otros muchos estaba tan combatida que ni el yugo del matrimonio ni el freno de la vergüenza fueron bastantes a detener la furia de su amor ni

\footnotetext{
${ }^{17}$ A. Estradé Sánchez, La segunda Diana de Alonso Pérez. Estudio y edición, ob. cit., pp. 474-475.

${ }^{18}$ Fols. 88R-88V.

${ }^{19}$ L. Rodríguez Peinado, «Los conejos y las liebres», en Revista Digital de Iconografía Medieval, III, 5 (2011), p. 12. Disponible en: https://www.ucm.es/data/cont/docs/621-2013-11-21-4.\%20Conejos\%20y\%20 liebres.pdf [Consultado 3-9-2018].

${ }^{20}$ M. de Cervantes, La Galatea, ob. cit., pp. 228-229.
} 
remediar la aspereza de su tormento, sino que, sus lamentables voces esparciendo y dolorosas lágrimas derramando, las duras peñas y fieras alimañas enternescía ${ }^{21}$.

Frecuentemente se refieren animales feroces que suelen presentarse no más que en sueños o visiones, es decir, ajenos a la acción real. Valga como ejemplo este pasaje de La Galatea, en el que el pastor Lisandro cuenta un sueño que tuvo:

Y, estando en esta pesadumbre, me pareció ver una blanca cierva junto a mí, a la cual yo ahincadamente suplicaba que, como mejor pudiese, apartase de mis hombros la pesada carga; y que, queriendo ella, movida de compasión, hacerlo, al mismo instante salió un fiero león del bosque, y, cogiéndola entre sus agudas uñas, se metía con ella por el bosque adelante; y que, después que con gran trabajo me había escapado del grave peso, la iba a buscar al monte, y la hallaba despedazada y herida por mil partes; de lo cual tanto dolor sentía, que el alma se me arrancaba sólo por la compasión que ella había mostrado de mi trabajo ${ }^{22}$.

Para más testimonios ajenos a la acción real, véanse estos versos que el pastor Manilio en La constante Amarilis, en los que las imágenes de las fieras sirven de paradoja para expresar el amor que le profesa a Amarilis:

Hará, pues, el cordero

al lobo; hará la liebre al león guerra;

y faltarán primero

los fuertes fundamentos de la tierra

antes que yo un instante

en amar su belleza y ser constante ${ }^{23}$.

\subsection{Animales fabulosos}

Después de la publicación de La Galatea, parece que la constitución de lo que hasta entonces había sido el género propio de los libros de pastores comienza a sufrir una serie de modificaciones en sus aspectos temáticos y argumentales, donde tienen cabida, entre otras cosas, elementos constitutivos de otros géneros narrativos de la época. Tanto es así que podemos observar cómo el ambiente pastoril acaba convirtiéndose en mero telón de fondo que el autor utiliza como pretexto para crear su ficción.

Este desfase ocurre, especialmente, en el siglo XVII, momento en el que las supuestas novelas de pastores constituyen novelas sui generis que, no obstante, no dejan de fascinar a sus lectores. Como puntualiza Avalle Arce:

\footnotetext{
${ }^{21}$ G. Gil Polo, Diana enamorada, ob. cit., p. 90.

${ }^{22}$ M. de Cervantes Saavedra, La Galatea, ob. cit., p. 199.

${ }^{23}$ M. A. Santorre Grau, Estudio y edición de La constante Amarilis de Cristóbal Suárez de Figueroa, Tesis Doctoral dirigida por Francisco López Estrada, Madrid, Universidad Complutense, Servicio de Publicaciones, 2002, p. 180.
} 
Son todas soluciones distintas al difícil género pastoril, y como tales, valiosas, pues nos revelan otras tantas actitudes ante un género consagrado en sus líneas generales de forma y contenido. [...] Dentro de su heterogeneidad nos ofrecen la comodidad de tener un común denominador: en todas se trata de presentar la sensibilidad del escritor y de su momento recubiertas con el pellico pastoril ${ }^{24}$.

Obviamente, el tratamiento de los animales se transforma considerablemente, pues las dulces y mansas ovejas, las aves que cantan armónicamente, los ciervos raudos y simpáticos, etc. han perdido la originalidad y resultan empalagosos. Ahora, el lector, se inclina por una ficción más macabra, en la que intervienen animales fabulosos, gigantescos y fantasmagóricos. Buen ejemplo de ello brinda -como se ha señalado hace poco tiempo ${ }^{25}$ - El premio, cuando el supuesto pastor se enfrenta, en primer lugar, a una perra enorme de carácter demoníaco ${ }^{26}$.

Fui la calle adelante y, apenas anduve seis passos, cuando sentí detrás de mí un ruido de cadenas espantoso cuanto con el silencio de la noche causava funestos ecos. Bolví los ojos sobresaltado y al instante vi una perra grandíssima que hazía el ruido con cinco o seis perrillos a los lados. Si en aquel instante no quedé muerto, a lo menos la color diera ostentación d'ello. Fui andando más aprissa y ella detrás de mí. [...] Iva poco a poco ella también. Al fin, antes de llegar a mi casa muy poco trecho, desembainé la espada, tirela y pareciome que la avía partido por medio. Vínose para mi derecha. Púseme con ella formando una pendencia grandíssima: a los bocados que me tirava, dávala la capa y parecía que me llebava cada vez un pedazo $^{27}$.

Por otro lado, ya casi al final de la narración de Arsindo, este se ve forzado a combatir con una serpiente gigantesca, a la que dará muerte poco después:

Fuime llegando y, assí que estuve cerca, tiré la piedra, di con ella en la otra, a cuyo sonido salió una sierpe horrible, espantable y, sobre todo, grandíssima, cuya visión os prometo me pudiera dar algún temor si no llevara la confiança dicha. Meto mano a mi espada y a mi daga. Póngome con ella, vínose para mí pensando de un bocado tragarme. Tirome con la boca una dentellada grande, por la cual le metí la espada y, aunque me llegó con las uñas al pecho, fue como si llegara a un bronze duro. Y aquella dureza infundiómela los untos de la yerva. Mas, a lo que yo entendí, el pecho me pareció que estava abierto ${ }^{28}$.

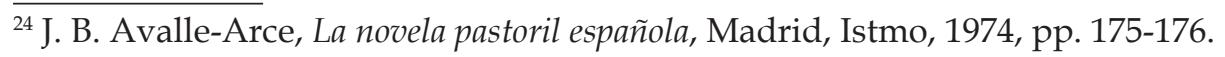

${ }^{25}$ F. J. González Candela, «Desde lo pastoril hacia la heterogeneidad narrativa: la mezcolanza de géneros en El premio de la constancia y pastores de Sierra Bermeja (1620) de Espinel Adorno», en Carlos Mata Induráin, Adrián J. Sáez y Ana Zúñiga Lacruz (eds.), «Sapere Aude». Actas del III Congreso Internacional Jóvenes Investigadores del Siglo de Oro (JISO 2013), Pamplona, Servicio de publicaciones de la Universidad de Navarra, Colección BIADIG (Biblioteca Áurea Digital) 24/Publicaciones digitales del GRISO, 2014, pp. 135-148. Disponible en: http://dadun.unav.edu/bitstream/10171/35933/1/JISO2013_11_Gonzalez. pdf [Consultado 03-09-2018].

${ }^{26}$ Véase C. Castillo Martínez, «Los libros de pastores: un género de éxito en el Siglo de Oro», art. cit., pp. 9-28.

${ }^{27}$ Fols. 73R-73V.

${ }^{28}$ Fol. 81R.
} 


\section{CONClusiones}

Los libros de pastores fueron un éxito en su momento ${ }^{29}$, es decir, sus características gustaban a los lectores. Una de de ellas era la fauna, o, mejor dicho, el tratamiento que recibían los animales que poblaban las páginas de estos libros, animales cuyas circunstancias se repetían una y otra vez. Tanto es así que, al pensar en libros de pastores, viene a la mente, casi de forma automática, el rebaño de ovejas mansas, las aves cantoras, etc., pues, acorde con la estética renacentista, los animales, como los personajes y su ambientación, siguen el canon idealizado.

Pero, como toda tendencia, la moda pastoril evolucionó y, llegado el siglo XVII, se modificó considerablemente. El Barroco literario comienza a desechar los moldes impuestos por el Renacimiento. En consecuencia, aquellos animales idealizados se convierten en entes repelentes, monstruosos y desproporcionados. ¿El motivo? Los libros de pastores desde la publicación de La Galatea comienzan a mezclar materiales procedentes de otros géneros literarios, hasta tal punto que las que se escribieron en el XVII solo pueden considerarse novelas pastoriles porque los personajes son pastores, pero la acción se aleja de la cuajada por Montemayor. Y la transformación, por supuesto, afectó también a los animales.

\section{BibliografíA}

Avalle-Arce, J. B., La novela pastoril española, Madrid, Istmo, 1974.

Castillo Martínez, C., «Los libros de pastores: un género de éxito en el Siglo de Oro», Per Abbat: Boletín Filológico de Actualización Académica y Didáctica, 6 (2008), pp. 9-28.

«El premio de la constancia y pastores de Sierra Bermeja (Madrid, 1620) de Jacinto de Espinel Adorno; la experiencia del más allá», en Actas del Congreso Internacional Antonio de Torquemada y la Literatura del Siglo de Oro, Juan Matas Caballero, José Manuel Trabado Cabado y Juan José Alonso Perandones (coords.), León, Universidad, 2005a, pp. 233-286.

, Antología de libros de pastores, Alcalá de Henares, Centro de Estudios Cervantinos, 2005b.

Cervantes SaAvedra, M. de, La Galatea, Francisco López Estrada y María Teresa López García-Berdoy (eds.), Madrid, Cátedra, 1995.

Covarrubias Herrera, J. de, La enamorada Elisea, Valladolid, BNM R/11214, 1594.

Espinel Adorno, J. de, El premio de la constancia y pastores de Sierra Bermeja, Madrid, BNM R/13353, 1620.

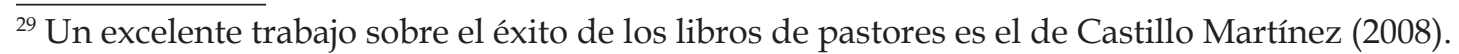


Estradé SÁnchez, A., La segunda Diana de Alonso Pérez. Estudio y edición, Tesis Doctoral dirigida por Miguel Álvaro Alonso, Madrid, Universidad Complutense, 2011. Gálvez de Montalvo, L., El pastor de Fílida, Miguel Ángel Martínez San Juan (ed.), Universidad de Málaga, Servicio de Publicaciones e Intercambio, 2007.

Gil Polo, G., Diana enamorada, Francisco López Estrada (ed.), Madrid, Castalia, 1987.

GonzÁlez Candela, F. J., «Desde lo pastoril hacia la heterogeneidad narrativa: la mezcolanza de géneros en El premio de la constancia y pastores de Sierra Bermeja (1620) de Espinel Adorno», en Carlos Mata Induráin, Adrián J. Sáez y Ana Zúñiga Lacruz (eds.), «Sapere Aude». Actas del III Congreso Internacional Jóvenes Investigadores del Siglo de Oro (JISO 2013), Pamplona, Servicio de publicaciones de la Universidad de Navarra, Colección BIADIG (Biblioteca Áurea Digital) 24/Publicaciones digitales del GRISO, 2014, pp. 135-148. Disponible en: http://dadun.unav.edu/bitstream/10171/35933/1/JISO2013_11_Gonzalez. pdf.

KRAUSS, W., «Localización y desplazamientos en la novela pastoril española», en Norbert Polussen y Jaime Sánchez Romeralo (coords.), Actas del Segundo Congreso Internacional de Hispanistas, Nimega, Instituto Español, 1967, pp. 363369.

León, Fray L. de, De los nombres de Cristo, Federico de Onís (ed.), Madrid, Clásicos Castellanos, I, 1914.

Lo Frasso, A. de, Los diez libros de Fortun de amor, Antonello Murtas (ed.), Cagliari, Centro di Studi Filologici Sardi CUEC, 2012.

López De Enciso, B., Desengaño de Celos, Madrid, BNM R/11558, 1596.

López Estrada, F., Los libros de pastores en la literatura española. La órbita previa, Madrid, Gredos, 1974.

Los Ángeles, Fray J. de, Considerationum espiritualium super libri Cantici Canticorum Salomonis, Madrid, NBAAEE, 1607.

Montemayor, J. de, La Diana, Juan Montero (ed.), Barcelona, Crítica, 1996.

RodríGuez PeINAdo, L., «Los conejos y las liebres», Revista Digital de Iconografía Medieval, III, 5 (2011), pp. 11-21. Disponible en: https://www.ucm.es/data/cont/ docs/621-2013-11-214.\%20Conejos\%20y\%20liebres.pdf.

Santana Sanjurjo, V., Edición de Ninfas y pastores de Henares de Bernardo González de Bobadilla (Alcalá de Henares, 1587), Tesis Doctoral dirigida por Antonio Cabrera Perera, Universidad de las Palmas de Gran Canaria, 2003.

Santorre Grau, M. A., Estudio y edición de La constante Amarilis de Cristóbal Suárez de Figueroa, Tesis Doctoral dirigida por Francisco López Estrada, Madrid, Universidad Complutense, Servicio de Publicaciones, 2002. 